\title{
A Resource-Based Perspective to Assess Firms' Profitability in the Food Industry: Evidence from the Italian Cheese Industry
}

\author{
Eugenio D'Angelo, (PhD) \\ Pegaso Telematic University, Naples, Italy
}

Doi: 10.19044/esj.2018.v14n4p1 URL:http://dx.doi.org/10.19044/esj.2018.v14n4p1

\begin{abstract}
The purpose of this paper is to investigate the determinants of firms' competitive advantage and performance in the Italian food industry, with specific reference to the cheese sector. This aim is consistent with the 3-year research program outlined by the agreement between the Pegaso Telematic University and the Gerardi \& Fortura Limited Liability Company, subscribed in November $2015(02 / 24 / 2015)$ and assigned to the author. The paper investigates the source of superior performance in the Italian cheese industry using the well-known Resource Based Theory. The empirical analysis is conducted on a sample of 110 firms and over a 10-year period of observation. An OLS regression is used to evaluate the impact of a bundle of resources on firms' performance. Findings show that physical and financial resources have the major effect on firms' return on assets, whereas intangible assets, capabilities and human resources have a lower and ambiguous effect.
\end{abstract}

Keywords: Resource-Based View, Performance, Food Industry

\section{Introduction}

The objective of this paper is to analyze the relationship between firms' resources and their performance in the Italian food industry, with a particular focus on the cheese sector. The focus of the paper origins form a 3 year research program defined by the agreement between the Pegaso Telematic University and the Gerardi \& Fortura Limited Liability Company, subscribed in November 2015 (02/24/2015). The paper addresses the theme of competitive advantage using the resource-based perspective (Barney, 1991), in order to determine which category of firms resources are more effective in generating superior performance. The need for an exploratory study in this field is useful mainly to detect entry barriers that may discourage a new player from investing in this industry and establish a cheese factory. 
The paper falls into four sections in addition to the introduction. In the first section we've provided a short literature review concerning the resourcebased theory, analyzing both the main theoretical aspects, including resources classification, and the main empirical works and the way in which they have operationalized the dependent and independent variables in empirical works. In the second section we've explained the methodology, including the sample definition and the variables description. In the third section we've presented the results of the study, including the descriptive statistics, the correlation analysis and the regression model. In the concluding section we've highlighted the main contribution of the paper, its limitations and some potential future research directions.

\section{Literature review}

The Resource-Based view is one of the most widely accepted theories inquiring firms' competitive advantage. It has its origin in the early nineties, when researchers felt unsatisfied by the structure-conduct-performance paradigm, described in the previous studies (Porter, 1984) and began to analyze internal sources of competitive advantage instead of external ones. In the industrial orientation perspective, indeed, performances were determined by the sector characteristics (the five forces described by Porter in 1979) and firms can gain competitive advantage choosing between price-leadership or differentiation strategies. With the resource-based perspective, researchers made a shift towards the company and its internal sources of competitive advantage. Following the work of Selznick (1957), concerning the distinctive competencies, and the one of Penrose (1959), concerning the system of productive resources, Wernerfelt (1984) and Barney (1991) developed this new approach to define the origin of the competitive advantage. Other works that have heavily influenced this stream of research have been the ones of Rumelt (1984, 1991), Grant (1996), Mahoney and Pandian (1992).

According to Barney (1991), firms can be seen as a bundle of resources that shape the preferred strategies consistently with the capability of firms to exploit these resources and generate competitive advantage and rents. The purpose of this theory is to demonstrate that the origin of competitive advantage and, consequently, of superior performance lies in firms' tangible and intangible resources that are distributed heterogeneously across them. However, among all the resources, only some of them are able to generate competitive advantage and, therefore, are defined as strategic resources. The VRIN criteria (Valuable, Rare, Inimitable and Non-substitutable) define the attribute that a strategic resource should have to generate competitive advantage. The resource should be valuable, because it has to be able to lead the firm to elaborate a strategy that can improve its efficiency and efficacy, thus reducing costs or increase revenues. Moreover, the resource should be 
rare, because in this way a firm can implement a unique strategy, because none of its competitors can replicate it. Lastly a valuable and rare resource, in order to generate a competitive advantage, need to be non imitable and non tradable on the market. In this way firms' competitor miss the chance to acquire or replicate it.

Therefore the two main assumptions of the resource-based paradigm are the heterogeneous distribution of resources and the non-transferability of them. The first concerns the generation of resources that derives, mainly, from the company's experience, while the second deals with the market imperfection. In other words, companies can gain competitive advantage if their resources have a cost to them that is lower than their economic value on the market (Jiang, 2014).

The literature concerning the classification of firms' resources usually differentiates between tangible and intangible resources, but this is not the only classification that can be made. According to Nothangel (2008), tangible and intangible resources can be grouped in six sub-categories. physical capital resources and financial capital resources are the categories in which tangible resources can be classified. On the other hand, intangible resources can be classified in four categories, such as routines (static and dynamic), intangible assets (patents, networks, reputation, brand name, culture), capabilities (technological, manufacturing, $\mathrm{R} \& \mathrm{D}$, marketing, learning, organizational, competitive, alliance) and human capital (Ceo and TMT, HR practices, HR skills and knowledge). However, a clarification must be added to this classification. Not all previous studies include human resources and capabilities among the company's resources. Indeed, often it is stated that capabilities are needed so that resources can express their potential in determining competitive advantage, particularly when firms have to face rapid changing environments (Grant, 1991; Mahoney, 1995; Teece et al. 1997).

According to Nothangel (2008), these different resources have been operationalized in different ways in previous studies. Farjoun (1998) measured physical assets as the sum of raw materials and other tangible asset; Miller and Shasie (1996) used property-based resources (such as buildings). Chatterjee and Singh (1999) measured financial resources using the leverage ratio and the current ratio; on the other hand, Helfat (1997) used firm pre-tax operating income divided by firm sales. Routines have been measured using formal administrative governance systems, as in Borch et al. (1999), or coding internal auditing mechanisms, as in Carmeli and Tishler (2004). Reputation has been measured in Carmeli and Tishler (2004) using the classification given by the American Most Admired Corporationns index, or using the media visibility in other works, as in Deephouse (2000). Culture has been measured using the Denisons's (Denison et al. 1995) organization culture model in previous studies as the one of Carmeli and Tishler (2004), or using a five- 
dimension scale in other studies, as the one of Zahra et al. (2004). The number of patents has been chosen by Schilling and Steensma (2002) to measure the technological capabilities, but in Spanos and Lioukas (2002) the same construct has been measured using the economies of scale and the technical experience. Organizational capabilities have been measured by Kraatz and Zajac (2001) using the organizational age, while in other works, such as in Lee and Miller (1999) the same construct have been measured with the investment of the companies in education and competence development. De Carolis (2003) measured marketing capabilities through marketing expenses, although other researcher, such as Spanos and Lioukas (2001) used output based competencies and not input based. Manufacturing capabilities have been investigated in Christmann (2000) through five items including equipment and machinery investment or technology in production. On the other hand, Schoeder et al. (2002) used three sub-scales, process and equipment, internal learning and external learning, to measure the same capabilities. Bergh (2001) used organizational tenure to measure human resources. The same has been done by Combs and Ketchen (1999) to measure TMT experience.

As previously mentioned, the purpose of the theory is investigating competitive advantage. However competitive advantage is not a synonymous of firm's performance, at least not directly. Of course the competitive advantage leads to the capability to extract rents and often scholars have measured competitive advantage through both short and long term ROA (Harrison et al. 1991), however other measures of competitive advantage have been employed, such as the improving of manufacturing costs or delivery speed (Bates and Flynn, 1995).

\section{Data and methodology}

We've gathered data from AIDA (Bureau van DijK). Our sample, consistently with what has been said in the introduction of the paper, needed to be made up of firms operating in the milk processing and dairy industry. Therefore, we've selected the sample according to the appropriate Italian Standard Industrial Classification (number 1051), restricting it to limited companies that are still active to date. This procedure reduced the sample from 808.586 to 1.430 firms. Afterwards, we selected only companies for which the data needed to conduct the investigation were available for all the ten-year period, from 2007 to 2016. This procedure led us to define the final sample of the study, which consisted of 110 companies. We used ten-year panel data to conduct the ordinary least squares (OLS) to estimate the parameters of the linear regression; therefore we finally had 1.100 observations. Data have been analyzed using SPSS17.

As mentioned in the literature review section, we can recognize and categorize resources as tangible or intangible. Tangible resources are typically 
related to physical and financial capital, whereas intangible resources are typically related to routines, intangible assets, capabilities and human capital.

Therefore, according to the resource-based theory of the firm and to the ways previous literature in the field has operationalized firms 'resources, we've defined the following independent variables to operationalize the resources employed by the firms to generate their competitive advantage:

Physical Capital

Tan = Tangible Assets / Total Assets - This variable is useful to evaluate firms ${ }^{6}$ investment in tangible assets such as machinery, equipment, buildings, etc.

Equip = Equipment / Total Assets - This variable has been used to evaluate the contribution to firms' performance given by tangible assets directly related to the productive process.

Prod = Value Added / Sales - This variable is a proxy of firms' productivity that, in this industry, mostly originates from tangible assets.

Financial Capital

NFP = Net Financial Position / Total Assets - This variable has been used to determine firm's dependency from financial debt.

$\mathrm{CR}=$ Current Assets / Current Liabilities - This variable is a proxy of firm's financial constraint.

$\mathrm{D} / \mathrm{E}=$ Long Term Debt / Equity - The capital structure needed a proxy to valuate firms' dependency from external resources.

OWC = Operating Working Capital / Sales - With this variable we've measured the investment in working capital.

$>\quad$ Intangible Assets

Patent $=$ Patent Investments $/$ Total Assets - This ratio explains the investment of firms in patents

$\mathrm{R} \& \mathrm{D}=\mathrm{R} \& \mathrm{D}$ Investments / Total Assets - This ratio is a proxy of the investments made by the firm in research and development.

Capabilities

Emp $=$ Value Added / Number of Employees - This variable explains the contribution of each employee to the value added.

Age $=$ Firm Age - This variable has been used to measure embedded capabilities of the firm that have been cumulated since its establishment.

Human Capital

$\mathrm{Ceo}=\mathrm{CEO}$ Tenure - The tenure of the CEO has been used as a proxy of the contribution of the leader to exploit resources in a given firm.

Board $=$ Number of board and directors member - This variable is suitable to determine the contribution of the human capital to the firm performance.

Firms' performances, on the other hand, have been measured by one dependent variable (Return On Assets), operationalized as follows: 
Performance

ROA = Net Income / Total Assets - The return on asset has been used to determine the firm performance as a proxy of the competitive advantage.

We employed a control variable to eventually take in account the effect of firms' dimension on the model.

$>\quad$ Control variable

Size $=$ Log Total Assets - Controlling for firms size is useful to determine if the dependent variable is influenced by the dimension of the companies.

Therefore the predictive model is specified as follows:

$\mathrm{Y}[\mathrm{ROA}]=\alpha+\beta_{1}$ Tan $+\beta_{2}$ Equip $+\beta_{3}$ Prod $+\beta_{4} \mathrm{NFP}+\beta_{5} \mathrm{CR}+\beta_{6} \mathrm{D} / \mathrm{E}+$ $\beta_{7} \mathrm{OWC}+\beta_{8}$ Patent $+\beta_{9} \mathrm{R} \& \mathrm{D}+\beta_{10}$ Emp $+\beta_{11}$ Age $+\beta_{12}$ Ceo $+\beta_{13}$ Board + $\beta_{14}$ Size $+\varepsilon$

\section{Result and discussion}

The statistical analysis, as motioned in the previous section, has been conducted on a sample of 110 firms in a ten-year period of observation. Even if we used a panel data analysis, in this section we will provide some information also regarding the trend of the employed variable in each year of analysis. In the first table we've displayed the descriptive statistics. We've provided, for each variable, the mean, the median, the lower and the higher value and the standard deviation (Table 1).

Table 1. Descriptive statistics

\begin{tabular}{cccccc}
\hline & Mean & Median & Min & Max & St.Dev \\
\hline ROA & $2,1 \%$ & $1,1 \%$ & $-77,7 \%$ & $50,0 \%$ & $6,0 \%$ \\
Tan & $31 \%$ & $30 \%$ & $0 \%$ & $79 \%$ & $18 \%$ \\
Equip & $11,0 \%$ & $8,6 \%$ & $0,0 \%$ & $59,3 \%$ & $9,4 \%$ \\
Prod & $32 \%$ & $30 \%$ & $4 \%$ & $100 \%$ & $13 \%$ \\
NFP & $16 \%$ & $18 \%$ & $-164 \%$ & $82 \%$ & $27 \%$ \\
CR & 1,59 & 1,23 & 0,08 & 40,62 & 1,94 \\
D/E & 0,8 & 0,3 & $-9,4$ & 89,7 & 3,1 \\
OWC & $16 \%$ & $11 \%$ & $-57 \%$ & $133 \%$ & $21 \%$ \\
Patent & $0,05 \%$ & $0,00 \%$ & $0,0 \%$ & $1,6 \%$ & $0,2 \%$ \\
R\&D & $0,2 \%$ & $0,0 \%$ & $0,0 \%$ & $6,7 \%$ & $0,6 \%$ \\
Emp & 208 & 137 & 19 & 5.896 & 307 \\
Age & 34 & 32 & 10 & 78 & 15 \\
Ceo & 2,49 & 2,60 & 0,59 & 8,65 & 0,84 \\
Board & 7 & 5 & 1 & 80 & 10 \\
Size & 9,80 & 9,69 & 6,58 & 15,22 & 1,27 \\
\hline
\end{tabular}

Source: Author's calculation on data AIDA (Bureau Van Dijk) 2007-2016.

The return on asset (ROA) shows a mean of $2,1 \%$ and a median of $1,1 \%$. If we look at the values reported in each year of observation, we see that the highest median value has been reported in 2016 an 2015 when it has reached the 3\%, while the lowest value has been achieved in 2007 when it was around $1,2 \%$. Tangible assets represent about the $30 \%$ of the investments in 
this sector. This value is confirmed by the cross sectional analysis, since the highest mean value has been reported in 2009 and the lower on in 2016, showing a range between $33,4 \%$ and $29 \%$. Investments in equipment are approximately the $11 \%$ of the total assets. This value has been confirmed in the entire period of analysis. The same persistent trend has been found concerning the productivity index, which has been around the $32 \%$ on average for all the period of investigation. The capital structure seems to be composed by analogue internal (equity) and external resources and approximately half of the external resources are gathered from the financial market. The current ratio is positive on average, showing a low average financial constraint for the firms in the sample. Intangible assets such as patent and R\&D expenses seem to be a really irrelevant investment in this industry. Firms have on average 32 years and this seems that we are mostly dealing with a first generation business. The CEO tenure is less than 3 years on average and the board and director size is on average composed of seven members.

The table reported above shows the Pearson's correlations between all the variables employed in the study (Table 2). The highest significant correlations are between tangible assets and equipment $(0,576)$, board and directors' number and the CEO tenure $(0,582)$, between firm size and CEO tenure and between firm size and the number of board members and directors.

Table 2. Correlation matrix

\begin{tabular}{|c|c|c|c|c|c|c|c|c|c|c|c|c|c|c|c|}
\hline & & & & & FP & CR & $\mathrm{D} / \mathbf{E}$ & OWC & Patent & R\&D & Emp & Age & Ceo & Board & Size \\
\hline$\overline{O A}$ & & $00^{*}$ & $117^{*}$ & & $28^{*}$ & , 144" &,$- 109^{*}$ &, 020 &,- 003 &,$- 121^{* *}$ &, $173^{*}$ & &, 054 & ,059 & 112 \\
\hline & & & & & &,$- 254^{\prime \prime}$ &, $084^{\prime \prime}$ & & & ,195" &,$- 183^{\prime \prime \prime}$ & &,- 057 &,$- 103^{\prime \prime}$ & 5 \\
\hline & & & & & & & 54 & & & & $127^{*}$ & & & & 06 \\
\hline & & & & & & & & & & & & & & & \\
\hline & & & & & & & & & & & & & & & 0 \\
\hline & & & & 65 &,$- 296^{*}$ & & & 2 & &,- 094 & & & & & \\
\hline & 19 & & & & ,14 & 04 & & , 00 & & & & & & & 0. \\
\hline & , 02 & 38 & &,$- 190^{*}$ & 289 & ,267 & & & $07^{* 4}$ & & &, 19 & &,- 206 & \\
\hline & ;,003 & & &, $247^{\circ}$ & 028 &,- 055 & &,$- 107^{*}$ & &, $167^{*}$ &,- 013 &, 061 & & ,062 & , 086 \\
\hline &,$- 121^{* *}$ &, $195^{\circ}$ & & ,061 &, $165^{\prime \prime \prime}$ &,$- 094^{* \prime}$ & &,- 035 & $167^{\prime \prime \prime}$ & &,- 072 &,- 015 & ,008 & (029, &, 02 \\
\hline np &, $173^{\circ \prime \prime}$ &,$- 183^{*}$ & & ,041 & 007 &,- 018 & &,$- 060^{\prime \prime}$ &,- 013 &,$- 072^{\circ}$ & &, $074^{\circ}$ & ,053 & $116^{*}$ & 26 \\
\hline & &,- 069 &,$- 193^{*}$ &, $208^{* 4}$ &,$- 123^{*+7}$ & 0. &,- & $194^{*}$ &, $061^{*}$ &,- 015 &, 074 & &,$- 096^{* 1+}$ &,- 021 & 14 \\
\hline & 054 & & & ,097, & , 040 &, 133 & & & & & 053, &,$- 096^{* 1}$ & & $882^{\prime \prime}$ & 57 \\
\hline & & & &, $186^{\circ}$ &,- 07 &, 05 & &,$- 206^{* 2 *}$ & & ,029, & & - -021 & $\overline{582}$ & & \\
\hline & & &,- 064 & ,041 &, $119^{\prime \prime}$ &, 015 &,- 032 & 05 & $086^{\circ}$ &, 023 & ,261" & $140^{*}$ &, 571 & & \\
\hline
\end{tabular}

Source: Author's calculation on data AIDA (Bureau Van Dijk) 2007-2016; **Correlations are significant at the 0,$01 ; *$ Correnaltions are significant at 0,05

Theese three correlation are clearly consistent with what we expected. Indeed, the equipment are part of the tangible assets and therefore we expected a positive and high correlation between these two variables. Morover, the board size is correlated with the firm size and with CEO tenure, probably because a larger firm is capable to hire more directors and to retain its CEO for a longer period of time. Surprisingly there is a low correlation between 
firm age and firm size and this can be interpreted as a positive aspect when investigating entry barriers to the industry.

The last table shows the result of the regression analysis (Table 3 ). The model results significant and with a adjusted r-square of 0,249, thus we can say that it can explain aproximately the $25 \%$ of the variance in the dependent variable. Moreover, the VIF analysis shows that there isn't a collinarity issue among the variables employed in the study. From the results of the regression model, observing the values of the standardized coefficients, it is possible to draw some conclusions about the resources that are most decisive in creating the competitive advantage in this industry.

Table 3. OLS regression analysis

\begin{tabular}{|c|c|c|c|c|}
\hline \multirow[b]{2}{*}{ Model } & \multicolumn{4}{|c|}{ ROA } \\
\hline & \multicolumn{2}{|c|}{$\begin{array}{l}\text { Standardized } \\
\text { coefficients }\end{array}$} & T-statistic & VIF \\
\hline Tan & \multicolumn{2}{|c|}{$-0,20 * * *$} & $-5,27$ & 2,15 \\
\hline Equip & \multicolumn{2}{|c|}{0,02} & 0,54 & 1,85 \\
\hline Prod & \multicolumn{2}{|c|}{$0,34 * * *$} & 10,50 & 1,51 \\
\hline NFP & \multicolumn{2}{|c|}{$-0,28 * * *$} & $-8,05$ & 1,73 \\
\hline $\mathrm{CR}$ & \multicolumn{2}{|c|}{0,02} & 0,77 & 1,35 \\
\hline $\mathrm{D} / \mathrm{E}$ & \multicolumn{2}{|c|}{$-0,05 * *$} & $-2,08$ & 1,04 \\
\hline OWC & \multicolumn{2}{|c|}{$0,07^{* *}$} & 1,98 & 1,88 \\
\hline Patent & \multicolumn{2}{|c|}{$-0,05^{*}$} & $-1,68$ & 1,20 \\
\hline R\&D & \multicolumn{2}{|c|}{$-0,05$} & $-1,62$ & 1,13 \\
\hline Emp & \multicolumn{2}{|c|}{$0,11 * * *$} & 3,72 & 1,18 \\
\hline Age & \multicolumn{2}{|c|}{$-0,15 * * *$} & $-5,12$ & 1,30 \\
\hline Ceo & \multicolumn{2}{|c|}{$-0,03$} & $-0,82$ & 1,85 \\
\hline Board & \multicolumn{2}{|c|}{$-0,17 * * *$} & $-4,21$ & 2,50 \\
\hline Size & \multicolumn{2}{|c|}{$0,22 * * *$} & 5,40 & 2,43 \\
\hline \multirow[t]{2}{*}{ Model summary } & R-Square & $\begin{array}{c}\text { Adjusted R- } \\
\text { Square }\end{array}$ & & \\
\hline & $25,9 \%$ & $24,9 \%$ & & \\
\hline \multirow{2}{*}{ ANOVA } & \multicolumn{2}{|c|}{$\mathrm{F}$} & & \\
\hline & \multicolumn{2}{|c|}{$28,816^{* * *}$} & & \\
\hline
\end{tabular}

Source: Author's calculation on data AIDA (Bureau Van Dijk) 2007-2016; ***Correlations are significant at the 0,$01 ; * *$ Correlations are significant at 0,$05 ; *$ Correlations are significant at the 0,10

First we can analyze the relationship between the variables concerning physical resources and the performance of companies. With regard to this aspect, we note that there is a significant and negative relationship between tangible assets and ROA. Moreover, performance are associated positively, but not significantly, with investments in machinery and equipment. Productivity, on the other hand, is strongly decisive in generating higher performances. With reference to variables representing the financial resources, it is noted that the dependence on financial sources (bank debts) is negatively associated with the performance of the companies. Similarly, in a general sense, as the presence of the debt in the capital structure increases, there is a negative effect on firm performances. The investments in working working 
capital and the current ratio, finally, are positively associated with the performances. With reference to the skills and contribution of human resources in determining the competitive advantage, it should be noted that the CEO's tenure does not seem to have any effect on performance, otherwise it can be said for the number of directors that is negatively associated with performance. Lastly, as far as capacities are concerned, the age of companies would appear to have had a negative effect on their performance, unlike what was foreseeable. On the other hand, staff productivity was positively associated with the dependent variable. Finally, the significance of the control variable relating to the size of the company is highlighted.

\section{Conclusion}

With this study it was intended to investigate the determinants of competitive advantage in the dairy sector. In the light of previous studies, it has been possible to classify company resources into four categories: physical, financial, capabilities and human resources. The statistical analysis showed that, in the companies of the sample, the selected bundle of resource somehow significantly influenced the performances. The results showed that the tangibility of the assets is a negative predictor of performance. This aspect would seem to support that companies do not succeed in taking advantage of their operational leverage, since the size of the company regarding tangible assets should allow better performance through the exploitation of industrial plants and warehouses. Basically, it could be said that companies are in a condition of oversizing. On the other hand, productivity, measured both through the ratio between added value and turnover and through the relationship between added value and the number of employees, has proved to be decisive for achieving competitive advantage. This aspect could be due to reasons of a commercial nature, as to aspects related to the ability to make the most of the workforce. Leverage seems to be negatively associated with performance as well as the dependency of the capital structure on external sources. It should be said that companies do not know how to exploit their financial leverage appropriately, meaning that operating profitability may be lower than the cost of third-party capital. We have already said about the capabilities of the workforce, but an element of thought arose also from the negative relationship between performance and the age of companies. Younger companies would seem to have an advantage in achieving higher performance than those who would have to gain a higher knowledge and ability through their experience. Finally, the CEO's tenure and the size of the administrative and control body both negatively affect performance. The picture that comes out of this analysis, especially if you want to read it in order to enter the sector through the creation of a new company, is that of an industry where the size of the company does not have a fundamental importance, the 
more important it is on the other hand, knowing how to properly size plants and equipment useful for production. Similarly, from the point of view of financing, it would seem that the most suitable source of financing could be the equity financing, perhaps due to the cost of third party capital, which could be particularly disadvantageous in this sector. Finally, there would not appear to be particular entry barriers caused by the experience of the company and of the administrative body. Clearly this article has obvious limitations, primarily concerning the sample size. In addition it is noted that a series of resources that are typically analyzed in the literature have not been included in the model due to lack of data. Therefore, in order to improve the study, it is considered necessary to develop the same on a numerically higher sample and integrating the model through the administration of a questionnaire that can detect the presence of strategic resources that could have significantly affected the determination competitive advantage.

\section{References:}

1. Barney, J. (1991). Firm resources and sustained competitive advantage. Journal of management, 17(1), 99-120.

2. Bates, K. A., \& Flynn, E. J. (1995, August). Innovation History and Competitive Advantage: A Resource-Based View Analysis of Manufacturing Technology Innovations. In Academy of Management Proceedings (Vol. 1995, No. 1, pp. 235-239). Academy of Management.

3. Bergh, D. D. (2001). Executive retention and acquisition outcomes: A test of opposing views on the influence of organizational tenure. Journal of Management, 27(5), 603-622.

4. Borch, O. J., Huse, M., \& Senneseth, K. (1999). Resource configuration, competitive strategies, and corporate entrepreneurship: An empirical examination of small firms. Entrepreneurship Theory and Practice, 24(1), 49-70.

5. Carmeli, A., \& Tishler, A. (2004). Resources, capabilities, and the performance of industrial firms: A multivariate analysis. Managerial and decision economics, 25(6-7), 299-315.

6. Chatterjee, S., \& Singh, J. (1999). Are tradeoffs inherent in diversification moves? A simultaneous model for type of diversification and mode of expansion decisions. Management Science, 45(1), 25-41.

7. Christmann, P. (2000). Effects of "best practices" of environmental management on cost advantage: The role of complementary assets. Academy of Management journal, 43(4), 663-680. 
8. De Carolis, D. M. (2003). Competencies and imitability in the pharmaceutical industry: An analysis of their relationship with firm performance. Journal of management, 29(1), 27-50.

9. Deephouse, D. L. (2000). Media reputation as a strategic resource: An integration of mass communication and resource-based theories. Journal of management, 26(6), 1091-1112.

10. Denison, D. R., \& Mishra, A. K. (1995). Toward a theory of organizational culture and effectiveness. Organization science, 6(2), 204-223.

11. Farjoun, M. (1998). The independent and joint effects of the skill and physical bases of relatedness in diversification. Strategic Management Journal, 611-630.

12. Grant, R. M. (1999). The resource-based theory of competitive advantage: implications for strategy formulation. In Knowledge and strategy (pp. 3-23).

13. Grant, R.M. (1996). Prospering in dynamically-competitive environments: organizational capability as knowledge integration. Org Sci 7(4):375-388

14. Harrison, J. S., Hitt, M. A., Hoskisson, R. E., \& Ireland, R. D. (1991). Synergies and post-acquisition performance: Differences versus similarities in resource allocations. Journal of management, 17(1), 173-190.

15. Helfat, C. E. (1997). Know-how and asset complementarity and dynamic capability accumulation: The case of R\&D. Strategic management journal, 339-360.

16. Jiang, W. (2014). Business Partnerships and Organizational Performance. Springer, Berlin, Heidelberg.

17. Ketchen, D. J., Hult, G. T. M., \& Slater, S. F. (2007). Toward greater understanding of market orientation and the resource-based view. Strategic management journal, 28(9), 961-964.

18. Kraatz, M. S., \& Zajac, E. J. (2001). How organizational resources affect strategic change and performance in turbulent environments: Theory and evidence. Organization Science, 12(5), 632-657.

19. Mahoney, J. T. (1995). The management of resources and the resource of management. Journal of business research, 33(2), 91-101.

20. Mahoney, J. T., \& Pandian, J. R. (1992). The resource-based view within the conversation of strategic management. Strategic management journal, 13(5), 363-380.

21. Miller, D., \& Shamsie, J. (1996). The resource-based view of the firm in two environments: The Hollywood film studios from 1936 to 1965. Academy of management journal, 39(3), 519-543. 
22. Nothnagel, K. (2008). Empirical research within resource-based theory: A meta-analysis of the central propositions. Springer Science \& Business Media.

23. Penrose, E. T. (1959). The theory of the growth ofthe firm. New York: Sharpe.

24. Porter, M. E. (1985). The value chain and competitive advantage. In: Competitive advantage: creating and sustaining superior performance. Free Press, New York

25. Porter, M. E., \& Porter, M. E. (1979). How competitive forces shape strategy.

26. Rumelt, R. (1984). Toward a strategic theory of the firm. Prentice-Hall, Englewood Cliffs

27. Rumelt, R. P. (1991). How much does industry matter?. Strategic management journal, 12(3), 167-185.

28. Selznick, P. (1957). Leadership in administration: A sociological interpretation. Berkeley. Cal. ISO 690

29. Schroeder, R. G., Bates, K. A., \& Junttila, M. A. (2002). A resourcebased view of manufacturing strategy and the relationship to manufacturing performance. Strategic management journal, 23(2), 105-117.

30. Spanos, Y. E., \& Lioukas, S. (2001). An examination into the causal logic of rent generation: contrasting Porter's competitive strategy framework and the resource-based perspective. Strategic management journal, 22(10), 907-934.

31. Schilling, M. A., \& Steensma, H. K. (2002). Disentangling the theories of firm boundaries: A path model and empirical test. Organization Science, 13(4), 387-401.

32. Teece, D. J., Pisano, G., \& Shuen, A. (1999). Dynamic capabilities and strategic management. In Knowledge and strategy (pp. 77-115).

33. Wernerfelt, B. (1984). A resource-based view of the firm. Strategic management journal, 5(2), 171-180.

34. Zahra, S. A., Hayton, J. C., \& Salvato, C. (2004). Entrepreneurship in family vs. Non-Family firms: A Resource-Based analysis of the effect of organizational culture. Entrepreneurship theory and Practice, 28(4), 363-381. 